\title{
Variability in Institutional Guidance for COVID-19- Associated Coagulopathy in the United States
}

\author{
Rushad Patell ${ }^{1, *}$ \\ Michael Jagla ${ }^{2} \odot$ Jason Freed $^{1}$ Nigel S. Key ${ }^{3}$ \\ ${ }^{1}$ Division of Hematology and Hematologic Malignancies, Beth Israel \\ Deaconess Medical Center, Boston, Massachusetts, United States \\ ${ }^{2} \mathrm{H}$. Lee Moffitt Cancer Center and Research Institute, University of \\ South Florida Morsani College of Medicine, Tampa, Florida, \\ United States \\ ${ }^{3}$ Division of Hematology and Oncology and Blood Research Center, \\ University of North Carolina at Chapel Hill, Chapel Hill, North \\ Carolina, United States \\ ${ }^{4}$ Division of Hematology and Oncology, Vanderbilt University Medical \\ Center, Nashville, Tennessee, United States \\ ${ }^{5}$ Department of Internal Medicine/Hematology, Yale School of \\ Medicine and Yale Cancer Center, New Haven, Connecticut, \\ United States \\ Thromb Haemost 2020;120:1725-1732.
}

The emergence of severe acute respiratory syndrome coronavirus 2 (SARS-CoV-2) in China in December 2019 has led to an ongoing global pandemic with more than 8.5 million cases and 460,000 deaths worldwide. ${ }^{1}$ Early reports from Wuhan, China, where the pandemic is believed to have originated, highlighted abnormal coagulation studies in patients, including elevated levels of D-dimer and fibrinogen, prolonged prothrombin time (PT), and mild thrombocytopenia. ${ }^{2-4}$ Severe coronavirus disease-2019 (COVID-19) is associated with pulmonary microvascular thrombosis, and arterial and venous thromboembolism that has been termed COVID-associated coagulopathy (CAC). ${ }^{5,6}$ The pathophysiology of CAC is incompletely understood, but includes upregulation of proinflammatory cytokines that promote immunothrombosis and endothelial dysfunction leading to widespread micro- and macrovascular thrombosis. ${ }^{7-10}$ These thromboembolic events are particularly prevalent in critically ill patients (35-45\%), even when compared with other critically ill patients with non-COVID-19 diagnoses (5-15\%). ${ }^{11}$ Although initial reports from China included patients who were not on thromboprophylaxis, the use of heparin thromboprophylaxis was shown to decrease mortality, especially in subsets of patients with higher D-dimer levels. ${ }^{12,13}$ Furthermore, studies from Europe have demonstrated high venous thromboembolism (VTE) rates despite the use of pharmacologic thromboprophylaxis. ${ }^{5}$

\footnotetext{
* Both authors contributed equally.
}

Address for correspondence Nigel S. Key, MD, Harold R. Roberts Distinguished Professor, 8008B Mary Ellen Jones Building, CB \#7035, 116 Manning Drive, Chapel Hill, NC 27599, United States (e-mail: nigel_key@med.unc.edu).

Given the concern for the heightened thrombotic risk and the contribution of the ensuing hypercoagulable state to the considerable morbidity and mortality of severe COVID-19, the role of anticoagulation beyond standard thromboprophylaxis for hospitalized medical patients has been raised. Currently, several drugs targeting the thromboinflammatory pathway in COVID-19 patients are under investigation, including parenteral and oral antithrombotics, antiplatelet, and fibrinolytic agents. $^{14}$

Notably, several clinical trials are currently underway to examine the role of higher than standard dose thromboprophylaxis and even therapeutic intensity anticoagulation prophylaxis in patients with COVID-19 (e.g., NCT04359277, NCT04345848, and NCT04344756). However, in the absence of randomized clinical trial data, numerous professional societies have published interim consensus recommendations to guide clinicians based on expert consensus and observational data (-Table 1). ${ }^{15-20}$ These documents universally recommend standard prophylactic doses of low molecular weight heparin (LMWH) or subcutaneous unfractionated heparin (UFH) for all hospitalized patients with COVID-19. In addition, monitoring of coagulation parameters, including platelet count, PT, D-dimer, and fibrinogen, are encouraged. The American Society of Hematology guidelines published in May 2020 specifies that therapeutic anticoagulation is not required unless documented indications such as VTE or atrial fibrillation are present. ${ }^{17} \mathrm{~A}$ notable specified exception is

(c) 2020. Thieme. All rights reserved. Georg Thieme Verlag KG,

Rüdigerstraße 14,

70469 Stuttgart, Germany
DOI https://doi.org/ $10.1055 / \mathrm{s}-0040-1715837$. ISSN 0340-6245.

accepted

July 22, 2020 
Table 1 Current societal guidance

\begin{tabular}{|c|c|c|}
\hline Source & Recommendation & Date Published \\
\hline \multirow{2}{*}{$\begin{array}{l}\text { International Society } \\
\text { on Thrombosis and } \\
\text { Haemostasis }^{18}\end{array}$} & Monitor: Platelet count, PT, D-dimer and fibrinogen & \multirow[t]{2}{*}{ March 25, 2020} \\
\hline & $\begin{array}{l}\text { Prophylactic LMWH should be considered in all patients who require hospitalization for } \\
\text { COVID-19 infection unless contraindicated (active bleeding, platelet }<25 \times 10^{9} / \mathrm{L} \text {; moni- } \\
\text { toring advised in severe renal impairment) }\end{array}$ & \\
\hline \multirow{2}{*}{$\begin{array}{l}\text { American Society of } \\
\text { Hematology } 17\end{array}$} & Monitor: Platelet count, PT/aPTT, D-dimer, and fibrinogen & \multirow[t]{2}{*}{ May 18, 2020} \\
\hline & $\begin{array}{l}\text { Prophylactic dose LMWH is recommended for all hospitalized COVID-19 patients despite } \\
\text { abnormal coagulation tests in the absence of active bleeding, and held only if plate- } \\
\text { let }<25 \times 10^{9} / \mathrm{L} \text {, or fibrinogen less than } 0.5 \mathrm{~g} / \mathrm{L} \\
\text { Therapeutic anticoagulation is not required unless VTE or atrial fibrillation is documented } \\
\text { Empiric therapeutic anticoagulation may be considered in the following cases when } \\
\text { imaging cannot be performed: intubated patients who develop sudden clinical and } \\
\text { laboratory findings highly consistent with PE, patients with physical findings of thrombosis } \\
\text { (i.e., superficial thrombophlebitis, cyanosis, thrombosis of dialysis filters/catheters/tub- } \\
\text { ing), or patients with respiratory failure with very high D-dimer and fibrinogen and in which } \\
\text { other causes have not been identified } \\
\text { All patients with COVID-19 who are started on empiric therapeutic anticoagulation for } \\
\text { presumed or documented PE should be given a minimum course of } 3 \text { months of the } \\
\text { therapeutic regimen } \\
\text { It is reasonable to consider extended thromboprophylaxis after discharge using a regula- } \\
\text { tory-approved regimen (e.g., betrixaban } 160 \text { mg on day } 1 \text { followed by } 80 \text { mg once daily for } \\
35-42 \text { days or rivaroxaban } 10 \text { mg daily for } 31-39 \text { days). Any decision to use postdischarge } \\
\text { thromboprophylaxis should consider the individual patient's VTE risk factors, including } \\
\text { reduced mobility and bleeding risk as well as feasibility } \\
\text { The use of LMWH or UFH in hospitalized critically ill patients should be considered because } \\
\text { of the shorter half-life and fewer drug-drug interactions compared with direct oral } \\
\text { anticoagulants and potential antiviral therapies }\end{array}$ & \\
\hline $\begin{array}{l}\text { American College } \\
\text { of Cardiology }\end{array}$ & $\begin{array}{l}\text { For hospitalized patients with COVID-19 and not in DIC or in suspected/confirmed DIC but } \\
\text { not overtly bleeding, prophylactic doses of anticoagulation can be administered to prevent } \\
\text { VTE with enoxaparin } 40 \text { mg daily or similar LMWH regimen (e.g., dalteparin } 5000 \text { U daily), or } \\
\text { UFH } 5000 \text { USC BID or TID for renal dysfunction. There is insufficient data to consider routine } \\
\text { therapeutic or intermediate-dose parenteral anticoagulation with UFH or LMWH } \\
\text { For patients with moderate or severe COVID- } 19 \text { and an indication for dual antiplatelet } \\
\text { therapy (e.g., PCI within the past } 3 \text { months or recent myocardial infarction) and with } \\
\text { suspected/confirmed DIC without overt bleeding, in the absence of evidence, decisions for } \\
\text { antiplatelet therapy need to be individualized. In general, it is reasonable to continue dual } \\
\text { antiplatelet therapy if platelet }>50,000 \text {, reduce to single antiplatelet therapy if } \\
25,000<\text { platelet }<50,000 \text {, and discontinue if platelet }<25,000 \\
\text { For patients with presentations concerning for STEMI and COVID-19, clinicians should } \\
\text { weigh the risks and severity of STEMI presentation with that of potential COVID-19 severity } \\
\text { in the patient, as well as risk of COVID- } 19 \text { to the individual clinicians and to the health care } \\
\text { system at large to inform decisions on primary percutaneous coronary intervention or } \\
\text { fibrinolytic therapy } \\
\text { Special attention should be also given to drug-drug interactions between antiplatelet } \\
\text { agents or anticoagulants, i.e., DOAC, and COVID-19 investigational therapies } \\
\text { Pharmacological prophylaxis for up to } 45 \text { days postdischarge should be considered if there } \\
\text { is elevated risk for thrombotic events (prior VTE, active cancer, major cardiopulmonary } \\
\text { disease) without high bleeding risk }\end{array}$ & April 15, 2020 \\
\hline $\begin{array}{l}\text { World Health } \\
\text { Organization }^{19}\end{array}$ & $\begin{array}{l}\text { Use pharmacological prophylaxis (LMWH [preferred if available] or heparin } 5000 \text { U SC BID) } \\
\text { in adolescents and adults without contraindications. For those with contraindications, use } \\
\text { mechanical prophylaxis (intermittent pneumatic compression devices) }\end{array}$ & March 13, 2020 \\
\hline \multirow[t]{2}{*}{$\begin{array}{l}\text { National Institutes } \\
\text { of Health }\end{array}$} & $\begin{array}{l}\text { Monitor: In nonhospitalized patients with COVID-19, there are currently no data to support } \\
\text { the measurement of coagulation markers (e.g., D-dimers, prothrombin time, platelet } \\
\text { count, fibrinogen) } \\
\text { In hospitalized patients with COVID-19, hematologic and coagulation parameters are } \\
\text { commonly measured, although there are currently insufficient data to recommend for or } \\
\text { against using this data to guide management decisions }\end{array}$ & \multirow[t]{2}{*}{ May 12, 2020} \\
\hline & $\begin{array}{l}\text { Patients who are receiving anticoagulant or antiplatelet therapies for underlying conditions } \\
\text { should continue these medications if they receive a diagnosis of COVID-19 } \\
\text { Any time anticoagulant or antiplatelet therapy is being used consideration must be given to } \\
\text { potential drug-drug interactions with other concomitant drugs. } \\
\text { Venous thromboembolism prophylaxis and screening: } \\
\text { Hospitalized adults with COVID-19 should receive VTE prophylaxis per the standard of care } \\
\text { for other hospitalized adults }\end{array}$ & \\
\hline
\end{tabular}


Table 1 (Continued)

\begin{tabular}{|c|c|c|}
\hline Source & Recommendation & Date Published \\
\hline & $\begin{array}{l}\text { LMWH or UFH may be preferred in hospitalized, critically ill patients because of their shorter } \\
\text { half-lives, ability to be administered intravenously or subcutaneously, and fewer drug-drug } \\
\text { interactions compared with oral anticoagulants } \\
\text { There are currently insufficient data to recommend for or against the use of thrombolytics } \\
\text { or increasing anticoagulant doses for VTE prophylaxis in hospitalized COVID-19 patients } \\
\text { outside the setting of a clinical trial } \\
\text { Patients with COVID-19 who experience an incident thromboembolic event or who are } \\
\text { highly suspected to have thromboembolic disease at a time when imaging is not possible } \\
\text { should be managed with therapeutic doses of anticoagulant therapy as per the standard of } \\
\text { care for patients without COVID-19 } \\
\text { Patients with COVID-19 who require extracorporeal membrane oxygenation or continuous } \\
\text { renal replacement therapy or who have thrombosis of catheters or extracorporeal filters } \\
\text { should be treated with antithrombotic therapy per the standard institutional protocols for } \\
\text { those without COVID-19 } \\
\text { Hospitalized patients with COVID-19 should not routinely be discharged on VTE prophy- } \\
\text { laxis, however, using Food and Drug Administration-approved regimens, extended VTE } \\
\text { prophylaxis can be considered in patients who are at low risk for bleeding and high risk for } \\
\text { VTE as per protocols for patients without COVID-19 }\end{array}$ & \\
\hline \multirow[t]{2}{*}{$\begin{array}{l}\text { Spanish Society } \\
\text { of Cardiology }\end{array}$} & $\begin{array}{l}\text { Monitor: It is proposed to monitor the proinflammatory and hemostatic parameters every } \\
24-48 \text { hours including C-reactive protein, D-dimer, IL-6, ferritin, and absolute lymphocyte } \\
\text { count }\end{array}$ & \multirow[t]{2}{*}{ April 22, 2020} \\
\hline & $\begin{array}{l}\text { Prophylactic LMWH (enoxaparin } 40 \mathrm{mg} / 24 \mathrm{~h} \text { or bemiparin } 3500 \mathrm{U} / 24 \mathrm{~h} \text { ) should be } \\
\text { considered in all patients who require hospitalization for COVID-19 infection unless } \\
\text { contraindicated (active bleeding, platelet }<20 \times 10^{9} / \mathrm{L} \text { ), with weight-adjusted doses for } \\
\text { patients with a body mass index }>35 \text { or renal impairment } \\
\text { If the patient does not have refractory respiratory insufficiency }\left(\mathrm{PaO}_{2} / \mathrm{FiO}_{2}<200 \text { or } \mathrm{SaO}_{2} /\right. \\
\mathrm{FiO}_{2}<300 \text { ), does not have a high risk of thromboembolism (determined by } 2 \text { or more of the } \\
\text { following proinflammatory parameters, } \mathrm{CRP}>15 \text {, D-dimer }>3 \times \mathrm{ULN} \text {, IL- } 6>40 \text {, ferri- } \\
\text { tin }>1000 \text {, and/or lymphocytopenia }<800 \text { ) and does not have a history of prior VTE or } \\
\text { ischemic vascular disease, prophylactic LMWH should be used } \\
\text { If the patient has refractory respiratory insufficiency but does not have high risk features } \\
\text { (criteria noted above), intermediate dose LMWH (enoxaparin } 1 \mathrm{mg} / \mathrm{kg} / 24 \text { h or bemiparin } \\
5000 \mathrm{U} / 24 \text { h) is recommended } \\
\text { If the patient has refractory respiratory insufficiency and high-risk features (criteria noted } \\
\text { above) or a high suspicion for VTE, high-dose LMWH (enoxaparin } 1 \text { mg/kg/12 h or bemiparin } \\
175 \mathrm{U} / \mathrm{kg} / 24 \text { h) is recommended } \\
\text { If the diagnosis of VTE is established, LMWH should be administered at therapeutic doses } \\
\text { Hospitalized patients who are receiving anticoagulant therapies for underlying conditions } \\
\text { should continue these medications if stable and do not meet criteria for severe disease or } \\
\text { may be transitioned to LMWH if they receive a diagnosis of COVID-19 (with adjustments for } \\
\text { renal insufficiency) } \\
\text { It is considered prudent to prolong the use of LMWH in prophylactic doses for } 7-10 \text { days } \\
\text { after discharge } \\
\text { In patients with an acute STEMI, even though primary angioplasty is the preferred } \\
\text { reperfusion strategy, fibrinolysis can be considered for infected patients with a poor clinical } \\
\text { situation that makes transfer difficult or who have a low bleeding risk and symptoms of } \\
\text { evolution }<3 \text { hours } \\
\text { If it is considered essential to use any of the antiviral treatments that interact with } \\
\text { clopidogrel or ticagrelor, then it would be reasonable to prescribe prasugrel }\end{array}$ & \\
\hline
\end{tabular}

Abbreviations: aPTT, activated partial thromboplastin time; BID, two times a day; COVID-19, coronavirus disease-2019; CRP, C-reactive protein; DIC, disseminated intravascular coagulation; DOAC, direct oral anticoagulant; IL, interleukin; LMWH, low molecular weight heparin; PCI, percutaneous coronary intervention; PE, pulmonary embolism; PT, prothrombin time; STEMI, ST-elevation myocardial infarction; TID, three times a day; UFH, unfractionated heparin; ULN, upper limit of normal; VTE, venous thromboembolism.

presumed VTE, such as acute respiratory decompensation in intubated patients with clinical and laboratory findings that are suggestive of VTE, when radiographic confirmation is not feasible. Epidemiologic data are currently lacking for postdischarge rates of VTE in COVID-19 patients, although factors including the hypercoaguable state of COVID-19, comorbidities, advanced age, and prolonged hospitalization may put these patients at higher risk. ${ }^{21}$ Of note, three of the existing guidelines recommend postdischarge thromboprophylaxis (-Table 1). ${ }^{16,17,20}$
Until more evidence-based guidelines for thromboprophylaxis are available, individual medical institutions have created their own institutional algorithms, presumably based on local individual expertise and consensus, as well as interim professional society and governmental recommendations. ${ }^{21,22}$ To assess the alignment of these institutional recommendations with published guidance from national and international professional societies and health authorities, we obtained local written algorithms from 15 large U.S. institutions across 11 U.S. states (-Table 2). Written treatment algorithms from these 


\begin{tabular}{|c|c|c|c|c|c|c|}
\hline 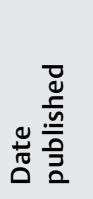 & 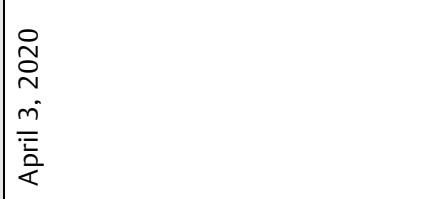 & 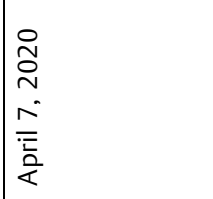 & 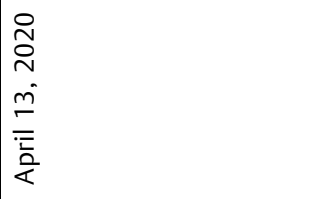 & 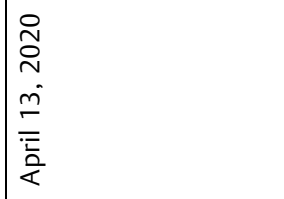 & 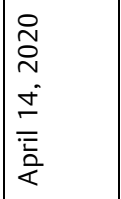 & 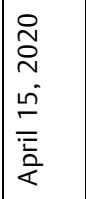 \\
\hline 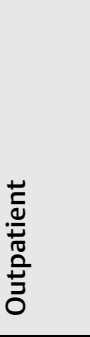 & 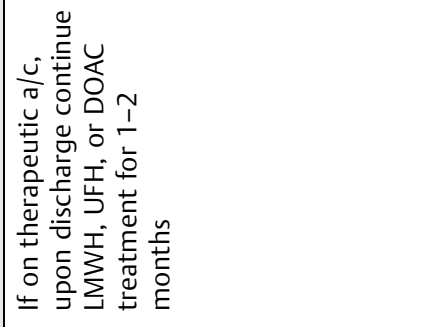 & & & 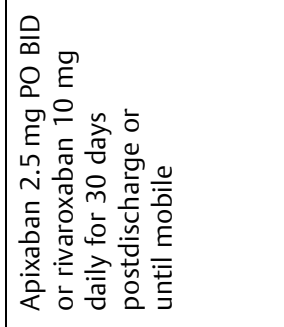 & & 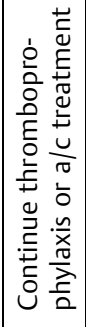 \\
\hline$\underline{Z}$ & 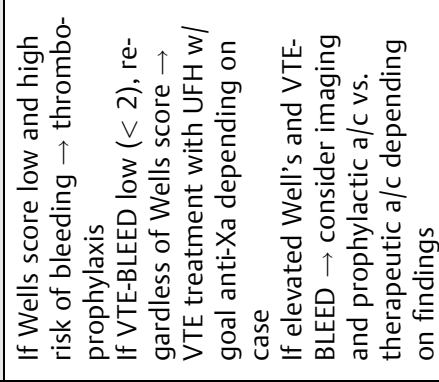 & \multirow{3}{*}{ 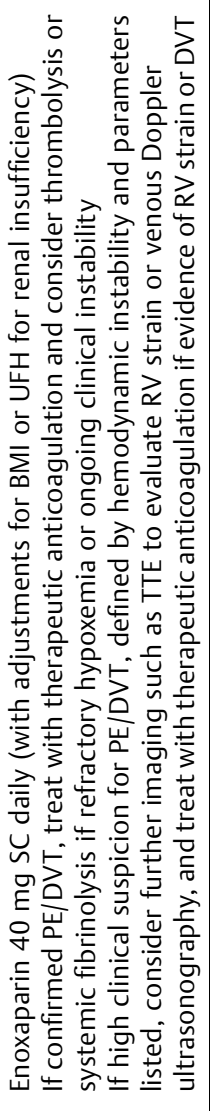 } & 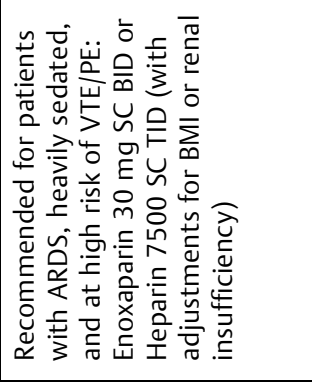 & \multirow{3}{*}{ 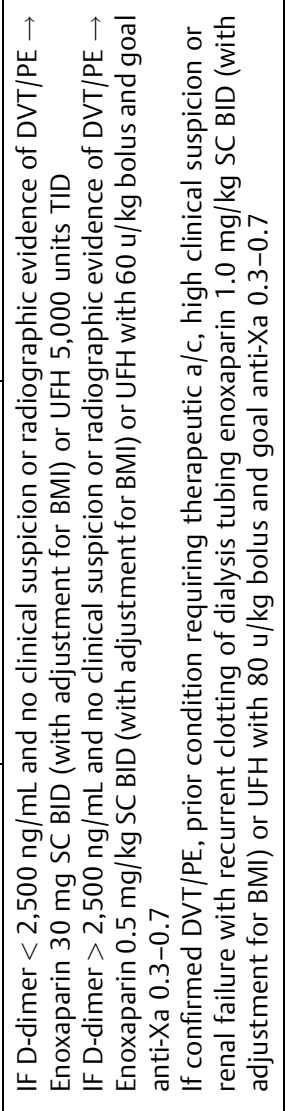 } & \multirow{3}{*}{ 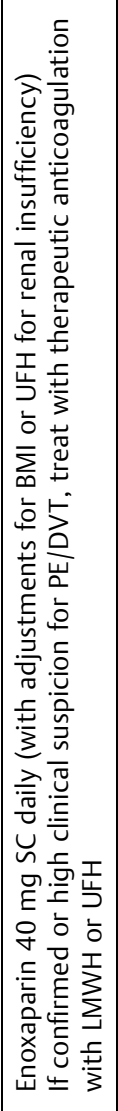 } & 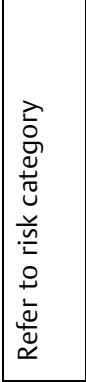 \\
\hline 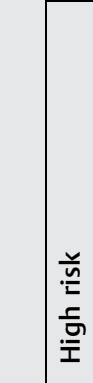 & 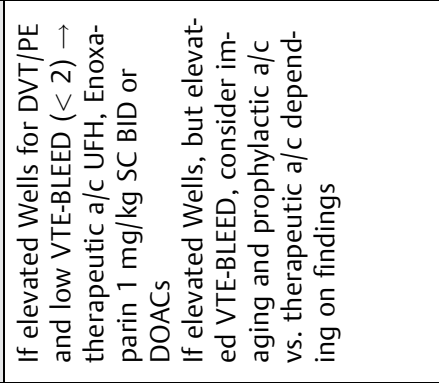 & & 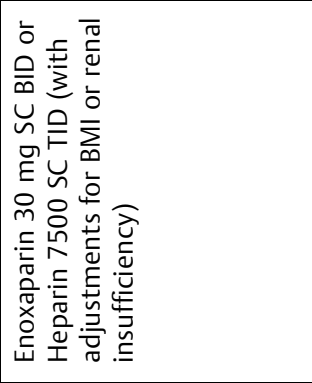 & & & 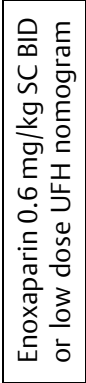 \\
\hline 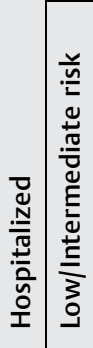 & 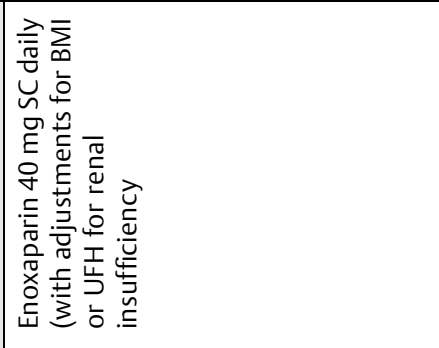 & & 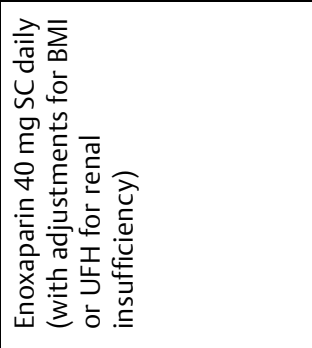 & & & 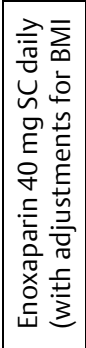 \\
\hline 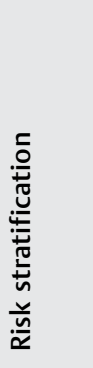 & 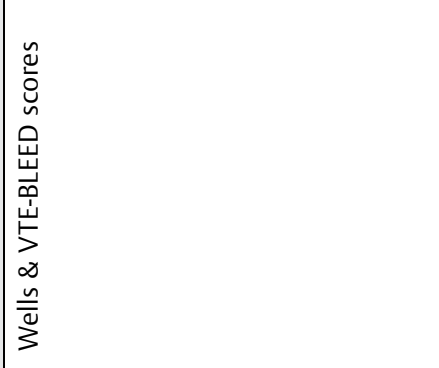 & 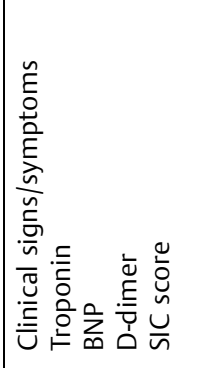 & 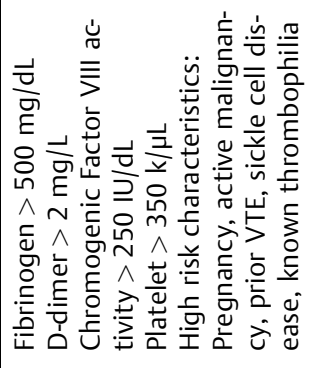 & 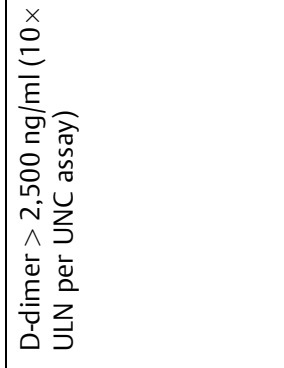 & & 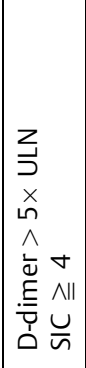 \\
\hline 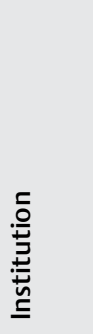 & 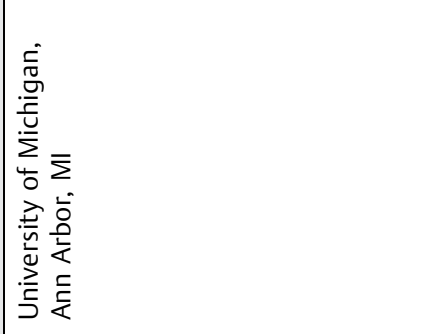 & 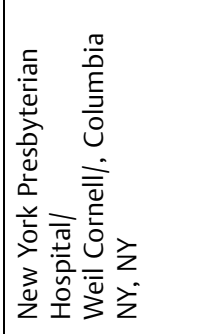 & 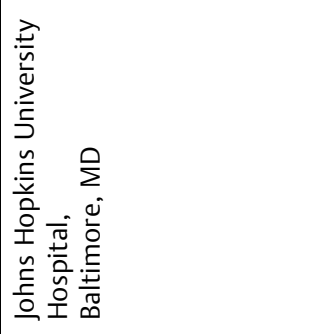 & 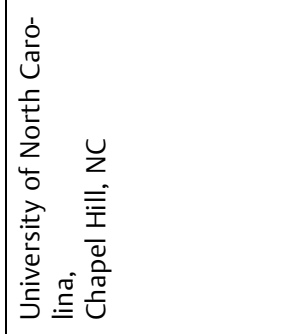 & 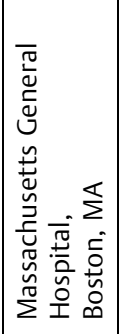 & \\
\hline
\end{tabular}









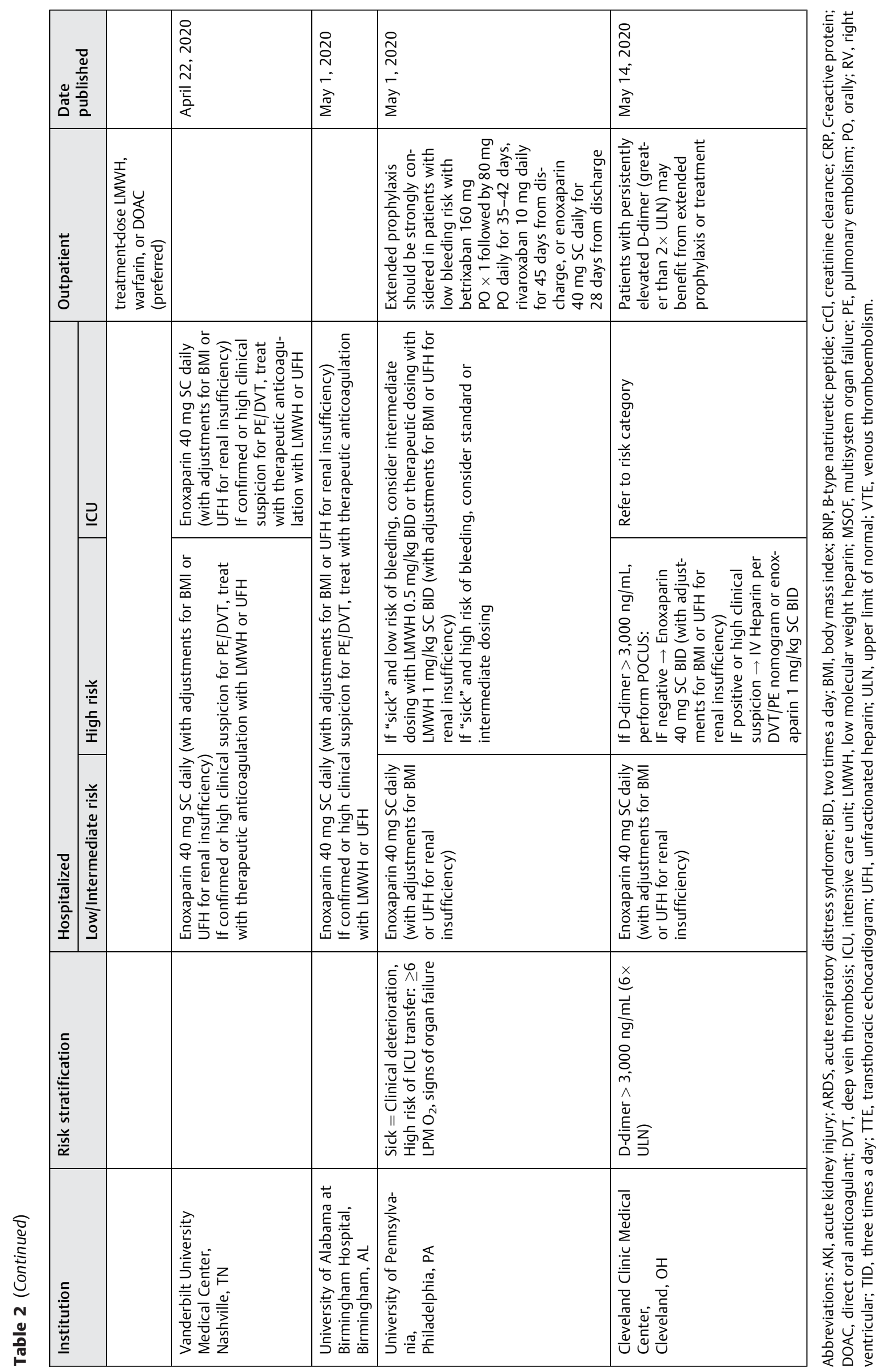


institutions were obtained by searching publicly available online algorithms or via a unique educational initiative, "Hematology and Oncology Inter-Institutional Collaborative Videoconferencing Learning," that brings together hematology and oncology fellowship trainees, faculty, and program leadership from these 15 institutions to share important updates and institutional best practices at the participating institutions.

Of the 15 centers, 4 institutional algorithms (Massachusetts General Hospital, Moffit Cancer Center/University of South Florida, University of Alabama, and Vanderbilt University Medical Center) are generally consistent with evidence-based thromboprophylaxis recommendations in non-COVID-19 populations, that is, enoxaparin $40 \mathrm{mg}$ subcutaneous daily (with adjustments for body mass index or renal insufficiency). Numerous laboratory and clinical parameters are recommended to risk-stratify hospitalized COVID-19 patients into intermediate or higher risk. Eight of the 15 institutions recommend using D-dimer thresholds to risk-stratify hospitalized COVID-19 patients into intermediate or higher risk, with different cutoffs recommended. For such "higher risk populations," anticoagulation strategies vary across the institutions. In 8 centers, use of an "intermediate" dose of LMWH $(0.4-0.6 \mathrm{mg} / \mathrm{kg}$ two times daily) is advised for this population. An additional 4 institutions advise full-dose anticoagulation with heparins (LMWH or UFH, three institutions) or direct oral anticoagulants (DOACs) (apixaban, one institution). Although bleeding has not been raised as a major concern in hospitalized patients with COVID-19, one institution (University of Michigan) recommends using clinical prediction rules to estimate a patient's thrombotic (Wells score) and bleeding (VTE-BLEED score) risks to guide individualized decisions regarding empiric use of high-dose or therapeutic anticoagulation. Almost all algorithms agree that for situations with a high clinical suspicion for VTE without confirmatory imaging, therapeutic anticoagulation with LMWH, UFH, or DOAC is recommended. One institution (Beth Israel Deaconess Medical Center), mentions consideration of empiric fibrinolysis for salvage therapy in severe and persistent hypoxia. Extended-duration thromboprophylaxis following hospitalization, especially in critically ill patients, has been shown to be effective in reducing VTE incidence in certain high-risk populations ${ }^{23,24}$; however, data specifically for COVID-19 patients are not yet available. ${ }^{25}$ Notably, among the 15 institutional protocols presented here, 8 include guidance on postdischarge outpatient thromboprophylaxis, recommending LMWH or DOACs for 1 to 3 months in selected higher risk subgroups.

The COVID-19 pandemic has pressurized the medical community to make medical decisions and recommendations based on limited anecdotal, observational, and in some cases, a complete absence of evidence. ${ }^{26}$ The observed increased risk for VTE has led institutional experts across the world and North America to create a variety of algorithms to guide anticoagulant use in this population, extrapolating from general experience from other subsets of patients with VTE. Here, we have collated guidelines from 15 U.S. institutions to: (1) allow comparison of similarities and differences in practice recommendations; (2) allow critical analysis of advantages and disadvantages of strategies proposed; and (3) allow other institutions both in the United States and abroad to strategize their preferred approach while awaiting more robust evidence. The wide disparity in institutional recommendations highlights the existing equipoise regarding antithrombotic management in patients with COVID-19, the lack of a true standard of care, and the need for data from robust, randomized prospective clinical trials to guide clinical practice.

Conflict of Interest

None declared.

\section{References}

1 Medicine JHUa. Coronavirus Resource Center. Available at: https://coronavirus.jhu.edu/map.html. Accessed May 16, 2020

2 Zhou F, Yu T, Du R, et al. Clinical course and risk factors for mortality of adult inpatients with COVID-19 in Wuhan, China: a retrospective cohort study. Lancet 2020;395(10229):1054-1062

3 Chen N, Zhou M, Dong X, et al. Epidemiological and clinical characteristics of 99 cases of 2019 novel coronavirus pneumonia in Wuhan, China: a descriptive study. Lancet 2020;395(10223):507-513

4 Wang D, Hu B, Hu C, et al. Clinical characteristics of 138 hospitalized patients with 2019 novel coronavirus-infected pneumonia in Wuhan, China. JAMA 2020;323(11):1061-1069

5 Connors JM, Levy JH. COVID-19 and its implications for thrombosis and anticoagulation. Blood 2020;135(23):2033-2040

6 Cao W, Li T. COVID-19: towards understanding of pathogenesis. Cell Res 2020;30(05):367-369

7 Levi M, Thachil J. Coronavirus disease 2019 coagulopathy: disseminated intravascular coagulation and thrombotic microangiopathy-either, neither, or both. Semin Thromb Hemost 2020

8 Klok FA, Kruip MJHA, van der Meer NJM, et al. Confirmation of the high cumulative incidence of thrombotic complications in critically ill ICU patients with COVID-19: an updated analysis. Thromb Res 2020;191:148-150

9 Oxley TJ, Mocco J, Majidi S, et al. Large-vessel stroke as a presenting feature of Covid-19 in the young. $\mathrm{N}$ Engl J Med 2020;382(20):e60

10 Demelo-Rodríguez P, Cervilla-Muñoz E, Ordieres-Ortega L, et al. Incidence of asymptomatic deep vein thrombosis in patients with COVID-19 pneumonia and elevated D-dimer levels. Thromb Res 2020;192:23-26

11 Levi M, Thachil J, Iba T, Levy JH. Coagulation abnormalities and thrombosis in patients with COVID-19. Lancet Haematol 2020;7 (06):e438-e440

12 Cui S, Chen S, Li X, Liu S, Wang F. Prevalence of venous thromboembolism in patients with severe novel coronavirus pneumonia. J Thromb Haemost 2020;18(06):1421-1424

13 Tang N, Bai H, Chen X, Gong J, Li D, Sun Z. Anticoagulant treatment is associated with decreased mortality in severe coronavirus disease 2019 patients with coagulopathy. J Thromb Haemost 2020;18(05):1094-1099

14 Bikdeli B, Madhavan MV, Gupta A, et al; Global COVID-19 Thrombosis Collaborative GroupPharmacological agents targeting thromboinflammation in COVID-19: review and implications for future research. Thromb Haemost 2020;120(07):1004-1024

15 Vivas D, Roldan V, Esteve-Pastor MA, et al. Recommendations on antithrombotic treatment during the COVID-19 pandemic. Position statement of the Working Group on Cardiovascular Thrombosis of the Spanish Society of Cardiology [in Spanish]. Rev Esp Cardiol 2020. Doi: 10.1016/j.recesp.2020.04.006

16 Bikdeli B, Madhavan MV, Jimenez D, et al; Global COVID-19 Thrombosis Collaborative Group, Endorsed by the ISTH, NATF, ESVM, and the IUA, Supported by the ESC Working Group on 
Pulmonary Circulation and Right Ventricular Function. COVID-19 and thrombotic or thromboembolic disease: implications for prevention, antithrombotic therapy, and follow-up: JACC stateof-the-art review. J Am Coll Cardiol 2020;75(23):2950-2973

17 COVID-19 and VTE/Anticoagulation: Frequently Asked Questions. American Society of Hematology. Available at: http://www.hematology.org/covid-19/covid-19-and-coagulopathy. Accessed May 19, 2020

18 Thachil J, Tang N, Gando S, et al. ISTH interim guidance on recognition and management of coagulopathy in COVID-19. J Thromb Haemost 2020;18(05):1023-1026

19 Clinical management of severe acute respiratory infection (SARI) when COVID-19 disease is suspected: Interim Guidance. Available at: http://www.who.int/docs/default-source/coronaviruse/clinical-management-of-novel-cov.pdf. Accessed April 27, 2020

20 Mahan CE, Burnett AE, Fletcher ML, Spyropoulos AC. Extended thromboprophylaxis in the acutely ill medical patient after hospitalization - a paradigm shift in post-discharge thromboprophylaxis. Hosp Pract (1995) 2018;46(01):5-15
21 Cohoon KP, Mahé G, Tafur AJ, Spyropoulos AC. Emergence of institutional antithrombotic protocols for coronavirus 2019. Res Pract Thromb Haemost 2020;4(04):510-517

22 Brenner B, Hull R, Arya R, et al. Evaluation of unmet clinical needs in prophylaxis and treatment of venous thromboembolism in highrisk patient groups: cancer and critically ill. Thromb J 2019;17(01):6

23 Coleman CI, Turpie AGG, Bunz TJ, Beyer-Westendorf J, Baker WL. Impact of prolonged anticoagulation with rivaroxaban on provoked venous thromboembolism recurrence: IMPROVE-VTE. Am J Med 2019;132(04):498-504

24 Cohen AT, Harrington RA, Goldhaber SZ, et al; APEX Investigators Extended thromboprophylaxis with betrixaban in acutely ill medical patients. N Engl J Med 2016;375(06):534-544

25 Rome BN, Avorn J. Drug evaluation during the Covid-19 pandemic. N Engl J Med 2020;382(24):2282-2284

26 COVID-19 Treatment Guidelines Panel. Coronavirus Disease. 2019 (COVID-19) Treatment Guidelines. National Institutes of Health. Available at: https://www.covid19treatmentguidelines.nih.gov/. Accessed May 17, 2020 